\title{
1 Assessment of the Effects of Horizontal Grid Resolution on 2 Long-Term Air Quality Trends using Coupled WRF-CMAQ 3 Simulations
}

4 Chuen-Meei Gan ${ }^{1,2}$, Christian Hogrefe ${ }^{1}$, Rohit Mathur ${ }^{1}$, Jonathan Pleim ${ }^{1}$, Jia Xing ${ }^{1}$, 5 David Wong ${ }^{1}$, Robert Gilliam ${ }^{1}$, George Pouliot ${ }^{1}$ and Chao $\mathrm{Wei}^{3}$

6 [1] Atmospheric Modeling and Analysis Division, NERL, ORD, U.S. Environmental Protection Agency, Research

7 Triangle Park, NC, USA, 27711

8 [2] CSC Government Solutions LLC, a CSRA company, Research Triangle Park, NC, USA, 27709

9 [3]Max Planck Institute for Chemistry, Mainz, Germany.

10 Correspondence to: Chuen-Meei Gan, CSRA Company (chuenmeei@gmail.com, Gan.Meei@epa.gov)

\section{Abstract}

14 The objective of this study is to determine the adequacy of using a relatively coarse horizontal 15 resolution (i.e. $36 \mathrm{~km}$ ) to simulate long-term trends of pollutant concentrations and radiation 16 variables with the coupled WRF-CMAQ model. WRF-CMAQ simulations over the continental 17 United State are performed over the 2001 to 2010 time period at two different horizontal 18 resolutions of 12 and $36 \mathrm{~km}$. Both simulations used the same emission inventory and model 19 configurations. Model results are compared both in space and time to assess the potential 20 weaknesses and strengths of using coarse resolution in long-term air quality applications. The 21 results show that the $36 \mathrm{~km}$ and $12 \mathrm{~km}$ simulations are comparable in terms of trends analysis for 22 both pollutant concentrations and radiation variables. The advantage of using the coarser $36 \mathrm{~km}$ 23 resolution is a significant reduction of computational cost, time and storage requirement which

24 are key considerations when performing multiple years of simulations for trend analysis. 25 However, if such simulations are to be used for local air quality analysis, finer horizontal 26 resolution may be beneficial since it can provide information on local gradients. In particular, 27 divergences between the two simulations are noticeable in urban, complex terrain and coastal 28 regions. 


\section{Introduction}

31 Typically, simulations spanning a year or less with regional-scale air quality model simulations

32 are used in air quality planning applications to estimate future air quality but recently many

33 studies are performing longer-term simulations to assess the abilities of these modeling systems

34 in capturing trends in air quality and air quality - meteorology interactions over time periods of

35 decreasing emissions (Hand et al. 2012, Gan et al. 2014, 2015 and Chin et al. 2014). However,

36 one of the challenges in performing such longer-term simulations is computational cost. A

37 variety of strategies have been adopted to meet this challenge. One is to utilize modeling

38 domains of limited geographic extent, but this increases the impact of boundary conditions on

39 the model results (Hogrefe et al., 2011). Another approach is to perform the model simulations at

40 a coarser horizontal resolution (i.e. $36 \mathrm{~km}$ ) than the $12 \mathrm{~km}$ resolution typically used in air quality

41 planning applications. In this study, we investigate this second approach by comparing results

42 from coupled WRF-CMAQ simulations performed over the continental United State (U.S.) for

4310 years $(2001-2010)$ at horizontal resolutions of 12 and $36 \mathrm{~km}$. We also evaluate the benefits

44 and drawbacks of using coarser horizontal resolution in long-term air quality applications. Both

45 simulations used the same emission inventory and model options.

46 Section 2 provides a brief overview of the configurations of the coupled model. The results from

47 the comparisons and methodologies are presented in Section 3. Finally, Section 4 discusses the 48 conclusions from our analyses.

\section{Model Simulations}

Simulations with the two-way coupled WRF-CMAQ model with aerosol feedback are analyzed in this study for 2001 to 2010.The WRF-CMAQ model was configured with WRFv3.4 and CMAQv5.02 (Wong et al. 2012). Two sets of model calculations were performed over a modeling domain covering the Continental U.S. (CONUS). One discretized the domain with grid cells of $36 \mathrm{~km}$ by $36 \mathrm{~km}$ and another with $12 \mathrm{~km}$ by $12 \mathrm{~km}$ grid cell resolutions. The vertical domain employed 35 vertical layers of varying thickness (between the surface and $50 \mathrm{hPa}$ ). The

57 comprehensive emission data is based on Xing et al. (2013) and the boundary conditions are obtained from a 108 x $108 \mathrm{~km}$ WRF-CMAQ hemispheric simulation (Xing et al. 2015).The 
comparable with each other, the $36 \mathrm{~km}$ simulation was regridded to the $12 \mathrm{~km}$ domain using

61 bilinear interpolation for the analysis presented in this study. In this method, each destination

62 point is mapped to a location in the source mesh andthe position of the destination point relative

63 to the surrounding source points is then used to calculate the interpolation weights

64 (http://www.ncl.ucar.edu/Document/Functions/ESMF/ESMF_regrid.shtml). Note that the result 65 of regridding the $12 \mathrm{~km}$ fields to the $36 \mathrm{~km}$ domain was found to be similar to regridding the 36 $66 \mathrm{~km}$ fields to the $12 \mathrm{~km}$ domain. Therefore, we present the latter in this manuscript as we are 67 trying to investigate whether using a coarser resolution is sufficient for trend analysis.

\section{Methodology and Results}

\subsection{Temporal Analysis}

71 To determine differences between the two simulations over the course of a year, we computed correlation coefficients and mean differences across space (i.e. non-water grid cell) for daily average all-sky shortwave (SW) radiation at the ground, clear-sky SW radiation at the ground, aerosol optical depth (AOD), and concentrations of total $\mathrm{PM}_{2.5}$, sulfate $\left(\mathrm{SO}_{4}^{2-}\right)$, elemental carbon (EC), nitrate $\left(\mathrm{NO}_{3}^{-}\right)$and ozone $\left(\mathrm{O}_{3}\right)$ for 2010. For each day and each variable, one-dimensional data arrays were constructed for both simulations using all non-water grid cells in the $12 \mathrm{~km}$ domain and the correlation coefficients and mean differences between these one-dimensional data arrays were then computed. For the calculation of differences, the $12 \mathrm{~km}$ results were subtracted from the regridded $36 \mathrm{~km}$ results. The resulting time series are shown in Figure 1 (the

80 correlation coefficients are shown in red and use the left y-axis while the differences are shown

81 in blue and use the right y-axis). For all-sky SW radiation, correlations between the two

82 simulations are highest during winter and decrease during summer when convection is stronger.

83 The correlation coefficients decrease to about 0.84 and differences between the two simulations

84 become as high as $\pm 4 \mathrm{~W} / \mathrm{m}^{2}$. The seasonal patterns of correlation coefficients and differences are

85 similar for clear-sky SW radiation but the correlations are higher and the differences are smaller.

86 AOD values for the $12 \mathrm{~km}$ simulations tend to be slightly higher than those for the $36 \mathrm{~km}$

87 simulations, especially during spring and summer. The correlation coefficients and differences

88 for total $\mathrm{PM}_{2.5}, \mathrm{SO}_{4}^{2-}, \mathrm{NO}_{3}^{-}, \mathrm{EC}$ and $\mathrm{O}_{3}$ show more intra-seasonal variability than $\mathrm{SW}$ radiation 
and AOD. While $\mathrm{PM}_{25}, \mathrm{SO}_{4}^{2-}$ and $\mathrm{NO}_{3}^{-}$show both positive and negative differences during all

90 seasons, EC differences are always positive, indicating higher concentrations in the $36 \mathrm{~km}$

91 simulations. In contrast, $\mathrm{O}_{3}$ values typically are slightly higher in the $12 \mathrm{~km}$ simulation. Overall,

92 the time series shown in Figure 1 indicate that systematic differences between the two

93 simulations are relatively small and tend to average out, especially when considering annual

94 averages.

95 In order to better illustrate systematic seasonal differences between the two sets of simulations, 96 the correlations and differences between maps (i.e. non-water grid cells) of monthly mean values 97 averaged over multiple years (2002, 2003, 2005, 2007, 2008, 2009 and 2010) are computed and 98 presented in Figure 2. Note that we excluded results from 2001, 2004 and 2006 since data from 99 January 2001 and January - April 2004 and 2006 were corrupted and including only partial-year 100 data from those years would have distorted the overall analysis. The results shown in Figure 2 101 confirm the presence of seasonal variations in correlation coefficients and differences as dicussed 102 in the previous paragraph based on 2010 data only.

103

\subsection{Spatial Analysis}

105 In addition to these seasonal cycles, we constructed maps of absolute differences in seasonal 106 average values between the $36 \mathrm{~km}$ and $12 \mathrm{~km}$ simulations for a typical year. For illustrative 107 purposes, we selected 2010, but the results are similar for other years. Only summer (June, July, 108 and August) and winter (November, December and January) results are shown in Figures 3 and 4 109 respectively because the differences are more significant in these two seasons. The left column 110 of Figures 3 and 4 shows the differences between the two simulations (i.e. $36 \mathrm{~km}$ minus $12 \mathrm{~km}$ ) 111 while the right column shows seasonal means from the $12 \mathrm{~km}$ resolution simulation. The 112 differences of seasonal mean surface concentrations of $\mathrm{PM}_{2.5}, \mathrm{SO}_{4}^{2-}, \mathrm{NO}_{3}^{-}, \mathrm{EC}$ and $\mathrm{O}_{3}$ averaged 113 over all non-water grid cells are relatively small as shown in Table 2. Moreover, the AOD from 114 the $12 \mathrm{~km}$ simulation are slightly higher than those from the $36 \mathrm{~km}$ simulation but the differences 115 are very small (e.g. summer different: -0.0018 unitless or -4.2\%). Lastly, the comparison of all116 sky SW radiation (see Figures $3(\mathrm{~g})$ and $4(\mathrm{~g})$ ) shows larger differences in coastal areas which 117 may be due to the effects of grid resolution on clouds while the comparison of clear-sky SW 118 radiation (see Figures 3 (i) and 4 (i)) shows smaller impacts of grid resolution that are primarily 
119 in areas of complex terrain. For example, the summer overall mean differences for all-sky and 120 clear-sky SW radiation are less than $1.7 \mathrm{~W} / \mathrm{m}^{2}$ or $0.55 \%$ and $0.0094 \mathrm{~W} / \mathrm{m}^{2}$ or $0.003 \%$ 121 respectively. The terrain height effect is confirmed in Figure 5 (a) which illustrates the difference

122 of the terrain height between the two resolutions. The contrast is most noticeable in higher terrain 123 areas where terrain difference patterns closely match clear-sky SW radiation differences (see 124 Figure 3 (i) and 4 (i)). In general, our results indicate that the differences tend to be highest in 125 areas of complex terrain, coastlines, and near major emission sources but the approximate 126 percentage of seasonal mean differences between the two simulations over land surface is less 127 than $9 \%$ and should not have a strong impact on simulated long-term trends; this is examined in 128 more detail in the following section.

\subsection{Trends Analysis}

131 While the results discussed above show that differences do exist between the two simulations for 132 a given year, they do not address the question whether such differences impact inferences on 133 temporal trends simulated by the two different model configurations, the primary metric of 134 interest when performing long-term simulations.

135 In order to further determine the effects caused by the different resolution, we assess the 10 years 136 summer trends $(2001-2010)$ of $\mathrm{PM}_{2.5}, \mathrm{SO}_{4}^{2-}$, AOD and both all-sky and clear-sky SW radiation 137 over the CONUS domain spatially. Note that, since data for several months in winter and spring 138 were corrupted for some years as discussed in Section 3.1, only summer trends (June, July and 139 August) are presented in this discussion. The right panel of Figure 6 shows the trends computed 140 based on the $12 \mathrm{~km}$ simulations. These results indicate decreasing trends of $\mathrm{SO}_{4}^{2-}, \mathrm{PM}_{2.5}$ and 141 AOD and an increasing trend of all-sky and clear-sky SW radiation especially in the eastern 142 U.S.. The left panel shows the differences of the trends between the two simulations (i.e. 143 regridded $36 \mathrm{~km}$ minus $12 \mathrm{~km}$ ); the differences are small relative to the absolute $12 \mathrm{~km}$ trends 144 (see Table 3 for a summary of trends and absolute and percentage trend differences averaged 145 over all non-water grid cells). For example, Figure 6 (j) illustrates that about $0.9 \mathrm{~W} / \mathrm{m}^{2} /$ year 146 increase of clear-sky SW radiation occurred over the eastern U.S. with the largest increases 147 occurring downwind of the Ohio River Valley, an area that experienced large decreases in $\mathrm{SO}_{2}$ 148 emissions during this time period (Xing et al., 2013). Figure 6 (i) shows the effect of model 
resolution on the trends is much smaller than the trend itself. The same finding holds true for

150 AOD as shown in Figures 6 (e-f), except that the sign of the change is reversed compared to

151 Figures $6(\mathrm{i}-\mathrm{j})$ since reduced emissions led to reduced aerosol loading and consequently to lower

152 AOD. Moreover, the trend results agree well with the results presented in Gan et al. [2014 and

153 2015] which utilized only the $36 \mathrm{~km}$ simulation. Note that the percent difference of all-sky SW is

154 more significant probably because the cloud simulation is more sensitive to the grid cell and

155 hence leads to higher differences in the all-sky radiation.

156 To complement the analysis of the trend maps shown in Figure 6, we also computed 10-year 157 trends of spatial average summer mean $\mathrm{PM}_{2.5}, \mathrm{SO}_{4}^{2-}, \mathrm{NO}_{3}^{-}, \mathrm{EC}, \mathrm{O}_{3}, \mathrm{AOD}$ and all-sky and clear158 sky SW radiation values from both simulations (Table 3). These trends were computed based on 159 a least square fit (LSF) of the summer mean model values averaged over all non-water grid cells 160 depicted in Figure 7. As shown in Figure 7 and Table 3, the results from both resolutions agree 161 well with each other providing confidence that using the $36 \mathrm{~km}$ horizontal resolution should be 162 sufficient for long-term air quality applications unless specific assessment of smaller targeted 163 areas such as urban, industrial and highly polluted areas is needed.

\section{Conclusion}

166 The results presented in this study show that differences in grid resolution for long-term coupled 167 WRF-CMAQ simulations can have seasonally varying effects on radiation, AOD and $\mathrm{PM}_{2.5}$ 168 concentrations. However, these differences are shown to be relatively small with the largest 169 differences being of an episodic nature. Consequently, longer-term averages tend to be less 170 influenced by differences in model configuration. Moreover, it was shown that changes over 171 time (i.e. long-term trends) in radiation, AOD, and particulate matter concentrations are 172 generally very similar between the $36 \mathrm{~km}$ and $12 \mathrm{~km}$ model configurations. Considering that the 173 computational burden associated with the $36 \mathrm{~km}$ model configuration is roughly seven times 174 lower than that of the $12 \mathrm{~km}$ model configuration, the results of this study suggest that using the 175 coarser model resolution is a viable option for long-term simulations and air quality planning 176 applications. Moreover, the storage requirement for the model output is about nine times smaller. 177 In particular, a coarser resolution simulation approach can help to estimate the long-range 178 transport of pollution over larger domains and longer time periods. However, if the focus of the 
application is on local sources and features, performing the simulations at finer grid resolution would be preferable (e.g. short-term field campaign studies such as Discover-AQ).

\section{Acknowledgements}

This research was performed while Chuen-Meei Gan held a National Research Council Research Associateship Award at US EPA. The research presented in this study was supported through an interagency agreement between the US Department of Energy (funding IA DE-SC0003782) and the US Environmental Protection Agency (funding IA RW-89-9233260). It has been subject to the US EPA's administrative review and approved for publication.

\section{References}

Appel, K. W., Pouliot, G. A., Simon, H., Sarwar, G., Pye, H. O. T., Napelenok, S. L., Akhtar, F., and Roselle, S. J.: Evaluation of dust and trace metal estimates from the Community Multiscale Air Quality (CMAQ) model version 5.0, Geosci. Model Dev., 6, 883-899, doi:10.5194/gmd-6-883-2013, 2013.

Chin, M., Diehl, T., Tan, Q., Prospero, J. M., Kahn, R. A., Remer, L. A., Yu, H., Sayer, A. M., Bian, H., Geogdzhayev, I. V., Holben, B. N., Howell, S. G., Huebert, B. J., Hsu, N. C., Kim, D., $\quad$ Kucsera, T. L., $\quad$ Levy, R. C., $\quad$ Mishchenko, M. I., $\quad$ Pan, X., Quinn, P. K., Schuster, G. L., Streets, D. G., Strode, S. A., Torres, O., and Zhao, X.-P.: Multi-decadal aerosol variations from 1980 to 2009: a perspective from observations and a global model, Atmos. Chem. Phys., 14, 3657-3690, doi:10.5194/acp-14-3657-2014, 2014.

Gan, C-M., Pleim, J., Mathur, R., Hogrefe, C., Long, C. N., Xing, J., Roselle, S. and Wei, C.: Assessment of the effect of air pollution controls on trends in shortwave radiation over the United States from 1995 through 2010 from multiple observation networks. Atmospheric Chemistry and Physics 14, no. 3 (2014): 1701-1715, 2014.

Gan, C.-M., Pleim, J., Mathur, R., Hogrefe, C., Long, C. N., Xing, J., Wong, D., Gilliam, R., and Wei, C.: Assessment of long-term WRF-CMAQ simulations for understanding direct aerosol effects on radiation "brightening" in the United States, Atmos. Chem. Phys., 15, 12193 12209, doi:10.5194/acp-15-12193-2015, 2015. 
Hand, J. L., Schichtel, B. A., Malm, W. C., and Pitchford, M. L.: Particulate sulfate ion concentration and $\mathrm{SO}_{2}$ emission trends in the United States from the early 1990s through 2010, Atmos. Chem. Phys., 12, 10353-10365, doi:10.5194/acp-12-10353-2012, 2012.

Hogrefe, C., Hao, W., Zalewsky, E. E., Ku, J.-Y., Lynn, B., Rosenzweig, C., Schultz, M. G., Rast, S., Newchurch, M. J., Wang, L., Kinney, P. L., and Sistla, G., 2011. An analysis of long-term regional-scale ozone simulations over the Northeastern United States: variability and trends, Atmos. Chem. Phys., 11, 567-582, doi:10.5194/acp-11-567-2011.

Wong, D. C., Pleim, J. E., Mathur, R., Binkowski, F. S., Otte, T. L., Gilliam, R. C., Pouliot, G., Xiu, A., Young, J. O. and Kang, D.: WRF-CMAQ Two-way Coupled System with Aerosol Feedback: Software Development and Preliminary Results. Geoscientific Model Development. Copernicus Publications, Katlenburg-Lindau, Germany, 5(2):299-312, 2012.

Xing, J., Pleim, J., Mathur, R., Pouliot, G., Hogrefe, C.,Gan, C.-M. and Wei, C.: "Historical gaseous and primary aerosol emissions in the United States from 1990-2010", Atmos. Chem. Phys., 13, 7531-7549, doi:10.5194/acp-13-7531-2013, 2013.

Xing, J., Mathur, R., Pleim, J., Hogrefe, C., Gan, C.-M., Wong, D. C., Wei, C., Gilliam, R., and Pouliot, G.: Observations and modeling of air quality trends over 1990-2010 across the Northern Hemisphere: China, the United States and Europe, Atmos. Chem. Phys., 15, 27232747, doi:10.5194/acp-15-2723-2015, 2015. 
Table 1: List of configurations

\begin{tabular}{ll}
\hline Parameter & Configuration \\
\hline Emission & Xing et al. [2013] \\
\hline Planetary Boundary Layer & ACM2 (Pleim 2007) \\
\hline Microphysics & Morrison 2-moment \\
\hline Gas-phase Chemistry & Carbon Bond 05 \\
\hline Aerosol Chemistry & aero6 (Appel et al., 2013) \\
\hline Land Surface & Pleim-Xiu \\
\hline Cumulus & Kain-Fritsch 2 \\
\hline Radiation & RRTMG SW \& LW \\
\hline Land use & NLCD 50 \\
\hline Boundary condition & Xing et al. [2015] \\
\hline
\end{tabular}

Table 2: Seasonal mean absolute and percentage differences $(36 \mathrm{~km}$ simulation minus $12 \mathrm{~km}$ simulation) averaged over all non-water grid cells for 2010. Trends for SW radiation are shown in $\mathrm{W} / \mathrm{m}^{2} /$ year, for AOD is shown in unitless/year, for ozone is shown in $\mathrm{ppbV/year}$ and for PM2.5, nitrate, sulfate and element carbon are shown in $\mu \mathrm{g} / \mathrm{m}^{3} /$ year.

\begin{tabular}{lcccc}
\hline & \multicolumn{2}{c}{ Summer } & \multicolumn{2}{c}{ Winter } \\
\hline Variable & mean & percent & mean & percent \\
\hline All-sky SW & 1.7022 & 0.551 & 0.6840 & 0.610 \\
\hline Clear-sky SW & -0.0094 & -0.003 & -0.1545 & -0.109 \\
\hline AOD & -0.0018 & -4.160 & 0.0003 & 0.863 \\
\hline PM2.5 & 0.1481 & 2.660 & 0.1865 & 1.990 \\
\hline Nitrate & 0.0090 & 8.200 & 0.0660 & 3.900 \\
\hline Element Carbon & 0.0213 & 9.420 & 0.0153 & 4.396 \\
\hline Sulfate & -0.0286 & -2.260 & -0.0094 & -0.720 \\
\hline Ozone & -0.7025 & -1.987 & -0.5262 & -1.907 \\
\hline
\end{tabular}

Table 3: Least-square fit trends and absolute and percentage trend differences $(36 \mathrm{~km}$

252 simulations minus $12 \mathrm{~km}$ simulations) averaged over all non-water grid cells. Summer (June,

253 July and August) average values for 2001 - 2010 were used in this analysis. Trends for SW

254 radiation are shown in $\mathrm{W} / \mathrm{m}^{2} /$ year, for AOD is shown in unitless/year, for ozone is shown in

$255 \mathrm{ppbV} /$ year and for $\mathrm{PM}_{2.5}$, nitrate, sulfate and element carbon are shown in $\mu \mathrm{g} / \mathrm{m}^{3} /$ year.

\begin{tabular}{lrrrrrrrr}
\hline \multicolumn{1}{c}{ Trend } & $\begin{array}{c}\text { Element } \\
\text { Carbon }\end{array}$ & Nitrate & \multicolumn{1}{c}{ Sulfate } & PM2.5 & \multicolumn{1}{c}{ AOD } & \multicolumn{1}{c}{ All-sky } & \multicolumn{1}{c}{ Clear- } \\
sky SW & \multicolumn{1}{c}{ Ozone } \\
\hline $36 \mathrm{~km}$ & -0.003 & -0.016 & -0.08 & -0.16 & -0.002 & 0.273 & 0.194 & -0.003 \\
\hline $12 \mathrm{~km}$ & -0.0034 & -0.0142 & -0.0775 & -0.1585 & -0.0018 & 0.2182 & 0.2303 & -0.0034 \\
\hline difference & 0.0004 & -0.0018 & -0.0025 & -0.0015 & -0.0002 & 0.0548 & -0.0363 & 0.0004 \\
\hline percentage & 12.50 & 11.92 & 3.17 & 0.94 & 10.53 & 22.31 & 17.11 & 12.50 \\
\hline
\end{tabular}


All-sky SW Radiaiton

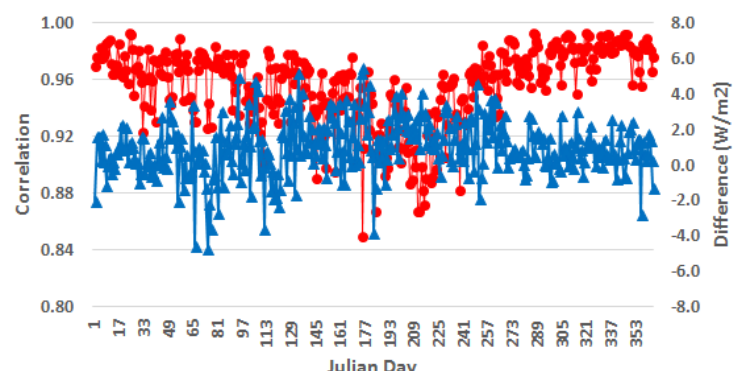

(a)

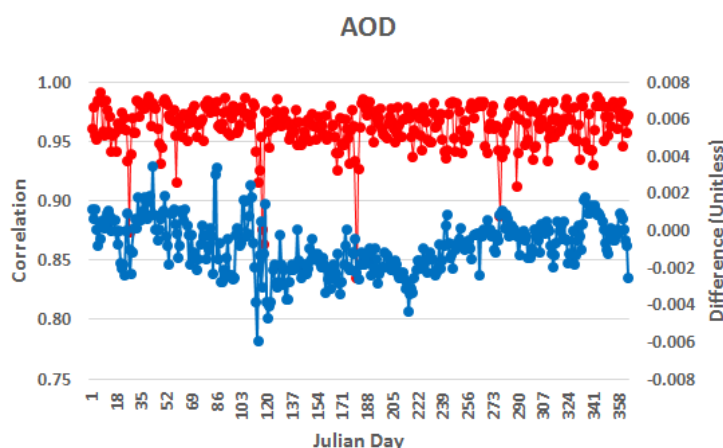

(c)

Julian Day

Element Corbon

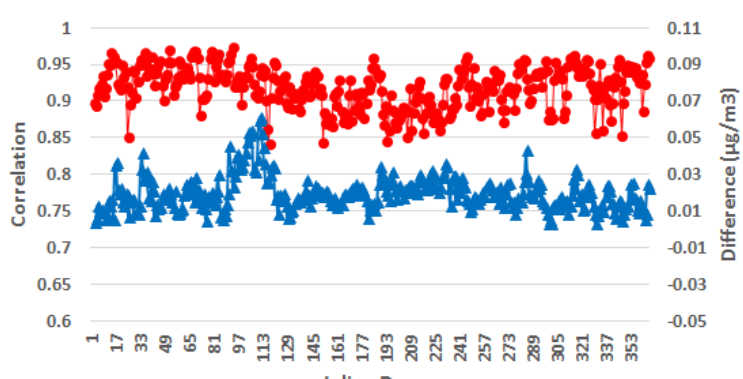

(e)

Julian Day

Nitrate

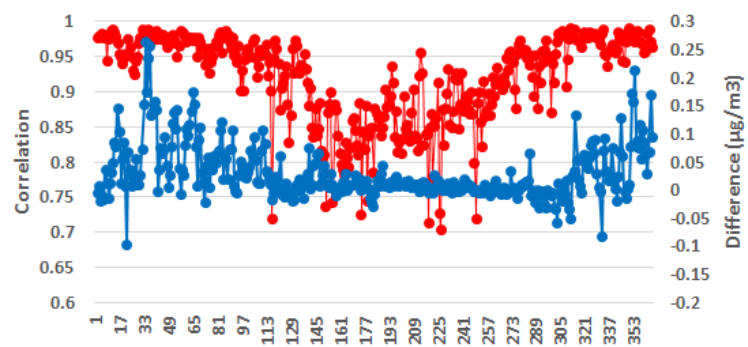

(g)

Julian Day (b)

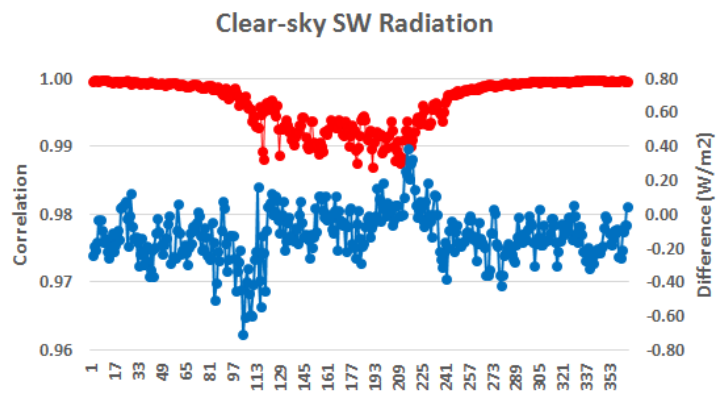

Julian Day

PM2.5

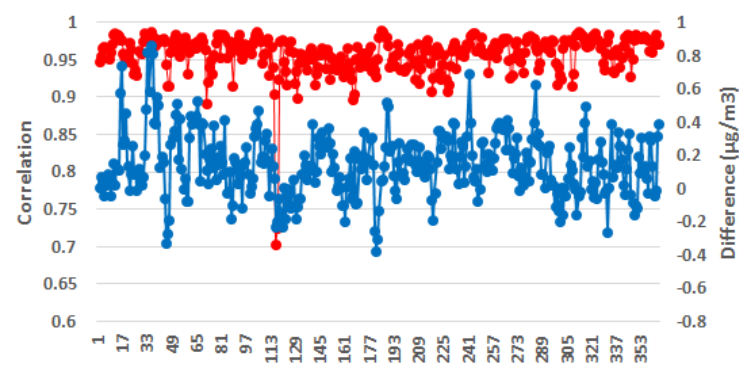

(d)

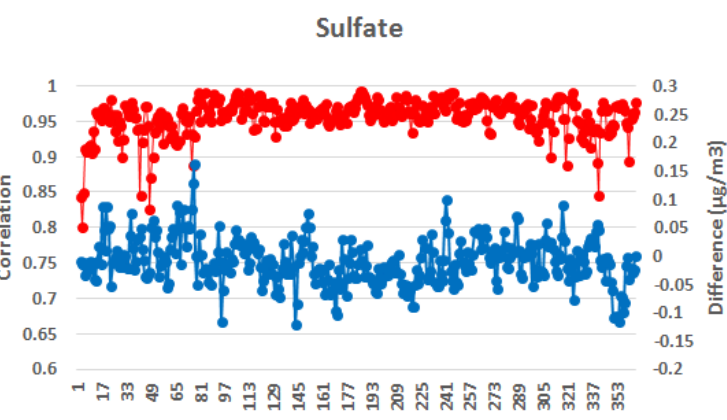

(f)

Julian Day

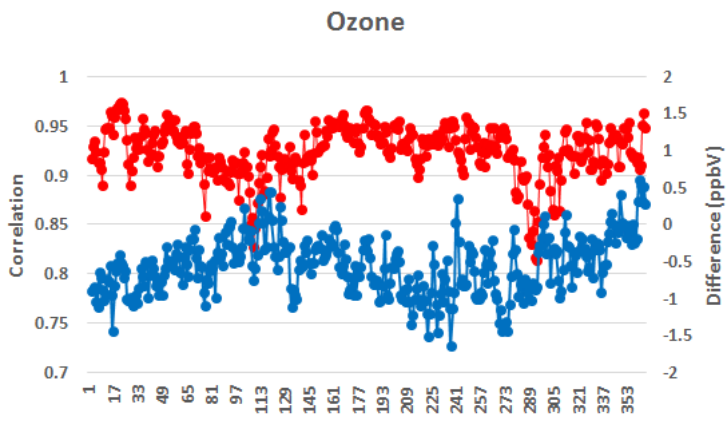

(h)

262 Figure 1: Time series of correlation coefficients (red, left y-axis) and differences (blue, right y263 axis) between the $36 \mathrm{~km}$ and $12 \mathrm{~km}$ simulation results computed across space from daily average 264 values for 2010. Further details on the computation of these time series are provided in the text. 

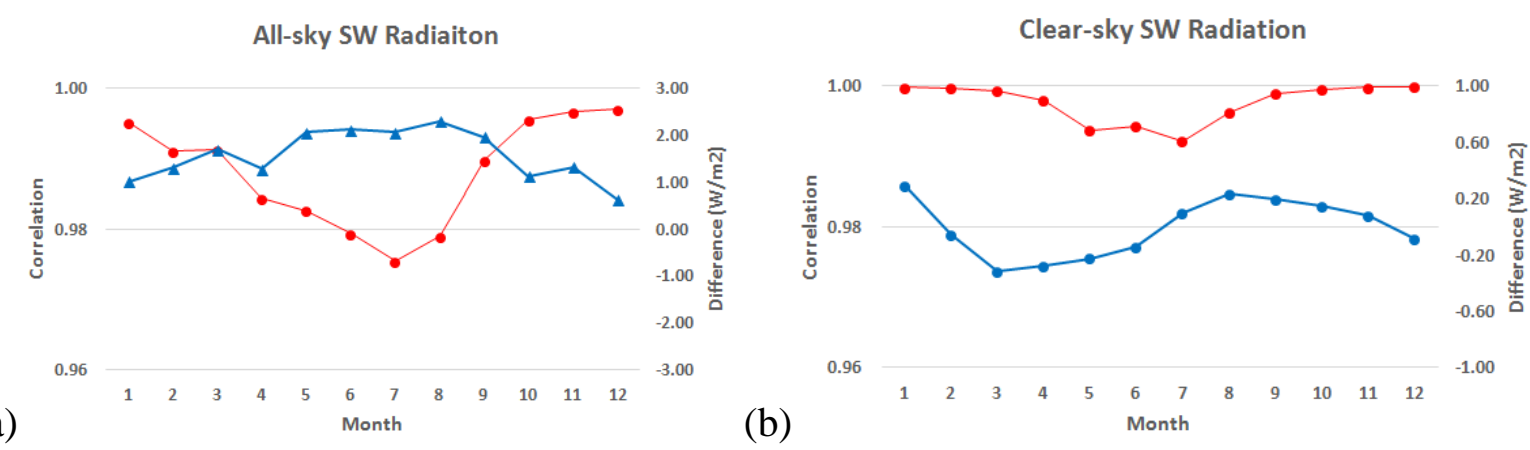

266

(a)

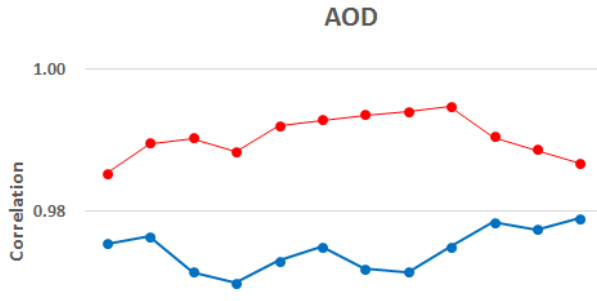

267

268

269

(e)

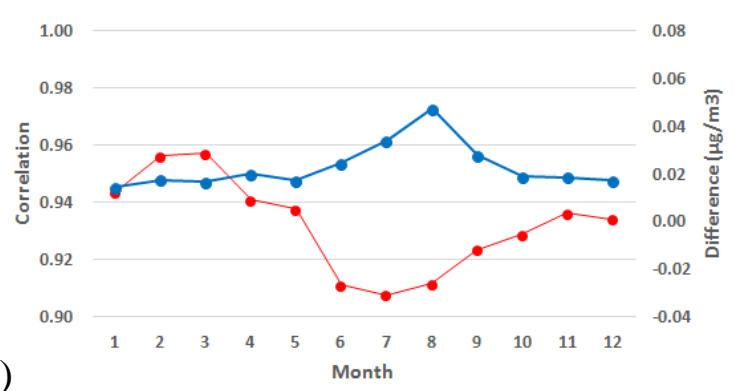

Nitrate

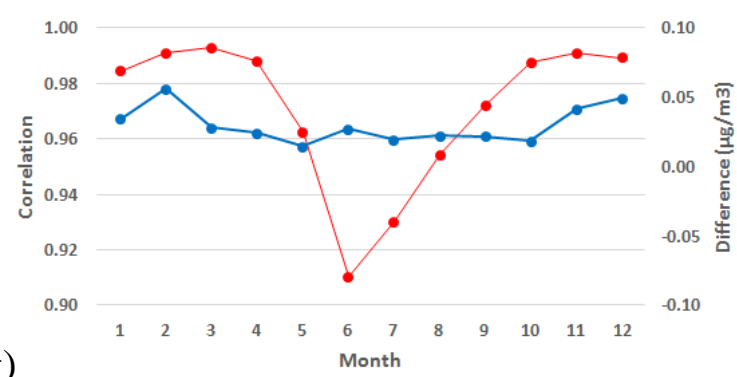

(g)

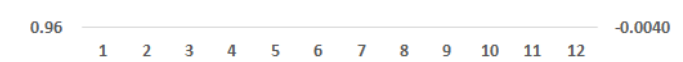

(c)

Element Corbon

(d)
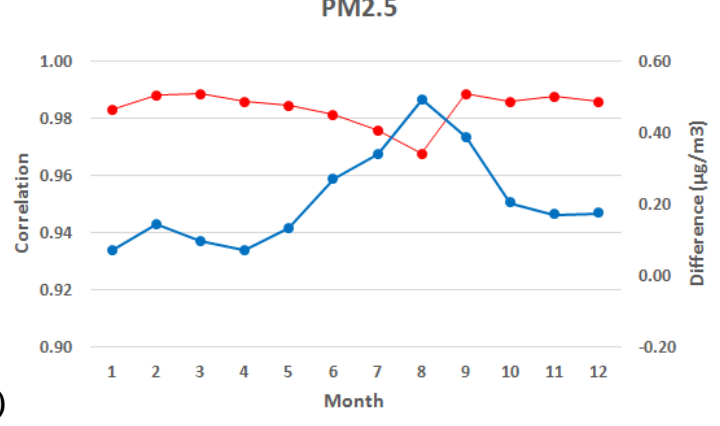

Sulfate

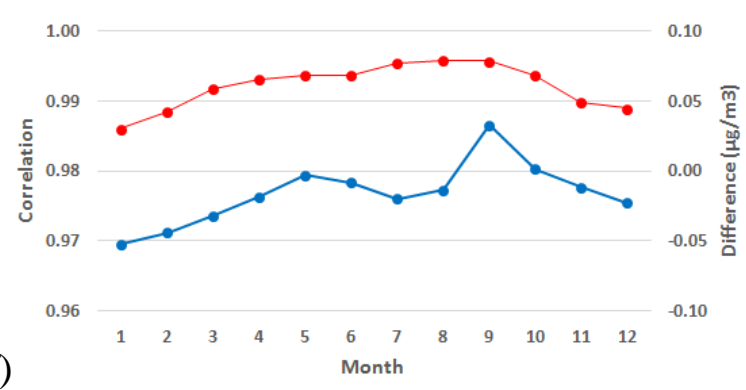

Ozone

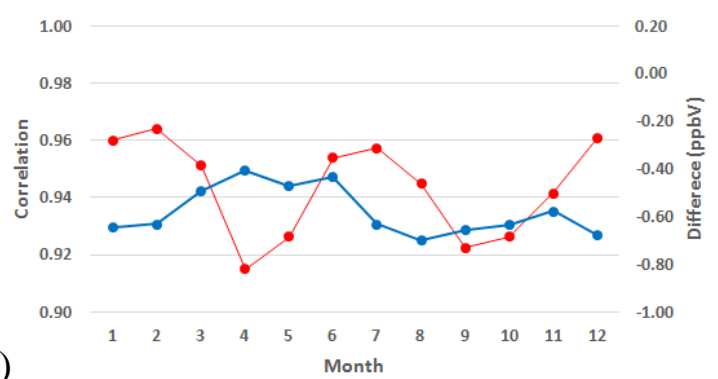

(h)

270 Figure 2: Time series of correlation coefficients (red, left y-axis) and differences (blue, right yaxis) between the $36 \mathrm{~km}$ and $12 \mathrm{~km}$ simulation results computed across space from monthly average values. Results were computed individually for 2002, 2003, 2005, 2007, 2008, 2009 and 2010 and then averaged over these seven years for display in this figure to illustrate systematic seasonal variations in correlation coefficients and differences between the simulations. Further 276 details on the computation of these time series are provided in the text. 

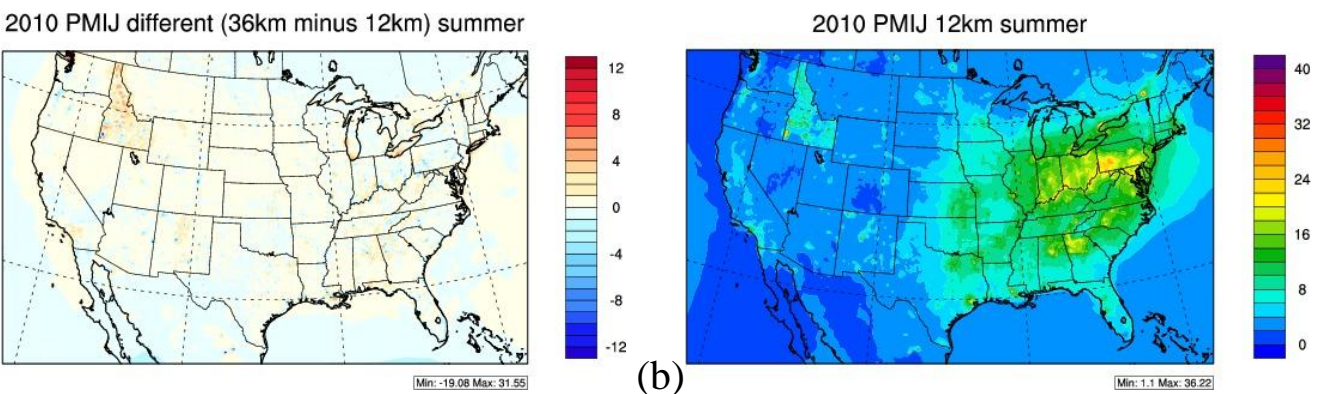

2010 ASO4IJ different ( $36 \mathrm{~km}$ minus 12km) summer

(b)
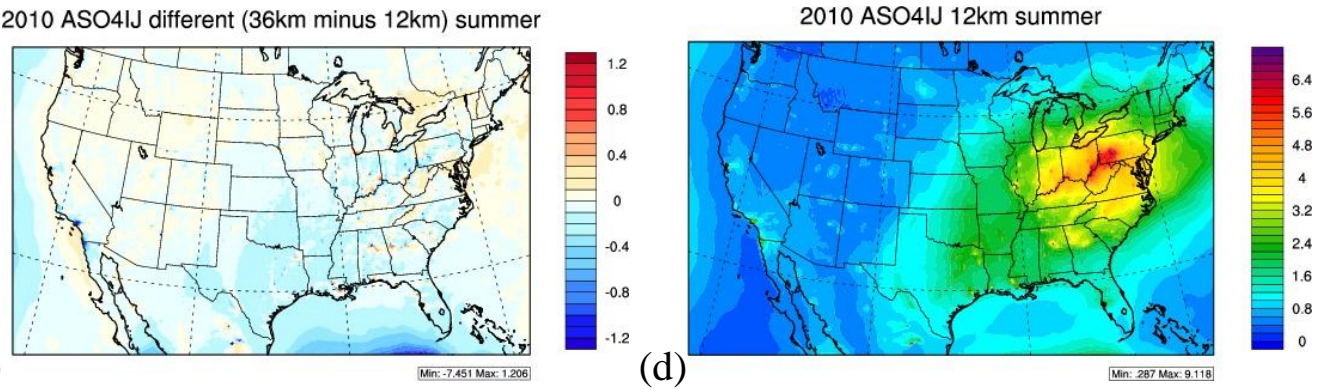

278

(c)

2010 SW_AOD_533 different (36km minus 12km) summer

279
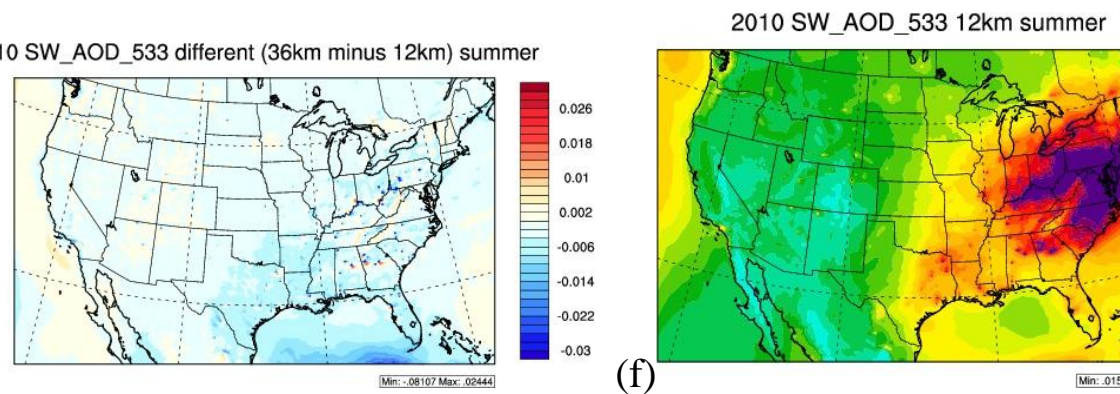

(e)
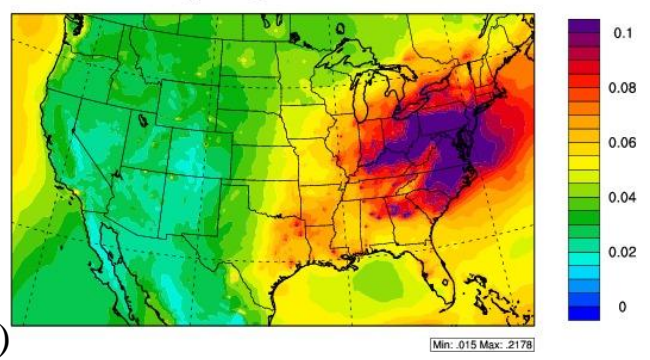

2010 SWDNB different (36km minus 12km) summer
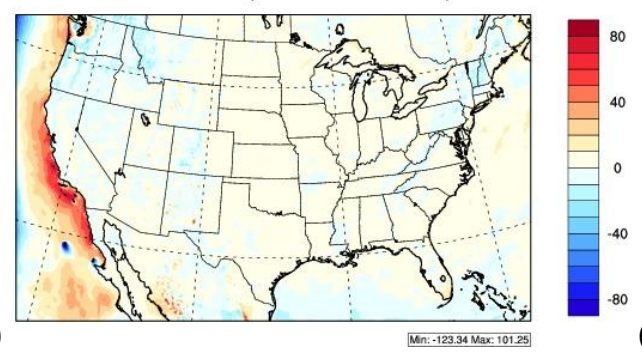

280

(g)

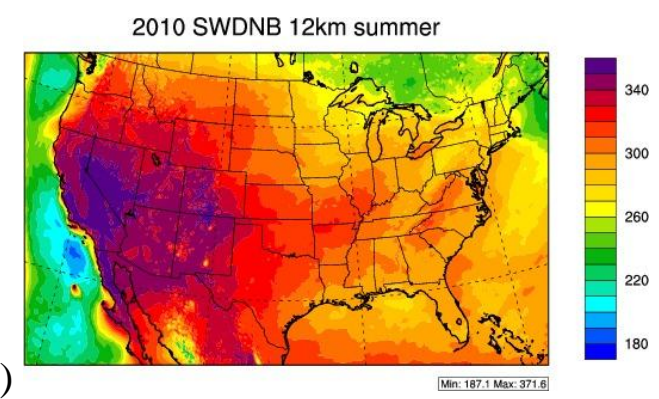

2010 SWDNBC different ( $36 \mathrm{~km}$ minus $12 \mathrm{~km})$ summer

(i)
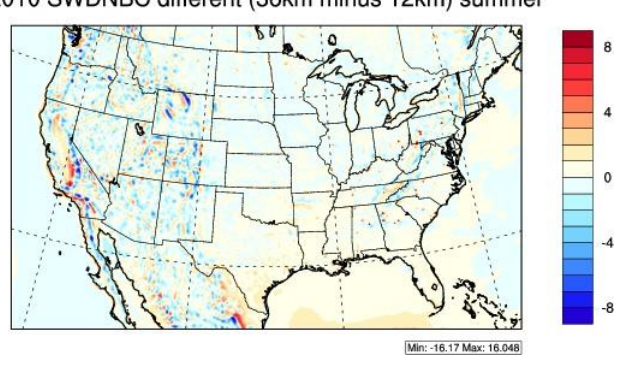

(j)

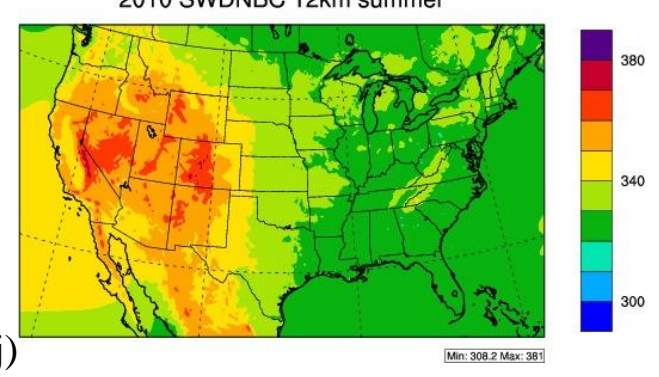

282 Figure 3: The first column shows the mean differences between the two simulations $(36 \mathrm{~km}$

283 minus $12 \mathrm{~km}$ ) and the second column shows the absolute values of $\mathrm{PM}_{2.5}, \mathrm{SO}_{4}^{2-}$, $\mathrm{AOD}$, all-sky 284 and clear-sky SW radiation. The results shown here are for the summer (June - August) of 2010. 
2010 PMIJ different (36km minus 12km) winter

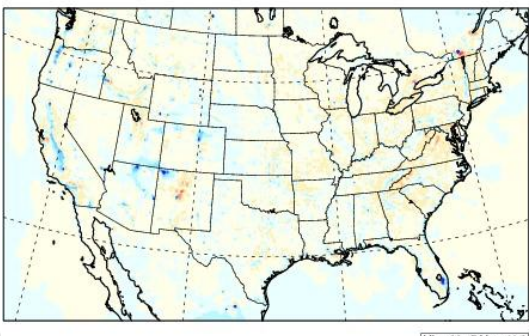

(a)

2010 ASO4IJ different (36km minus 12km) winter

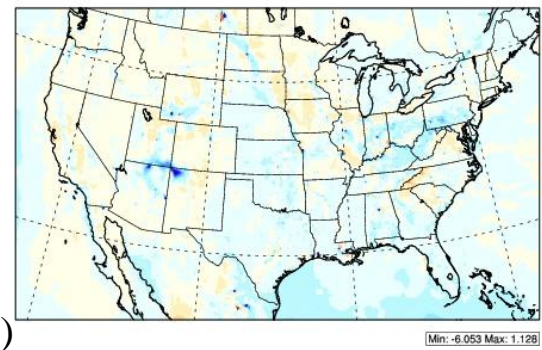

2010 SW_AOD_533 different (36km minus 12km) winter

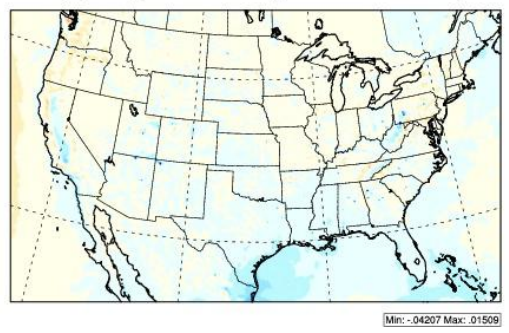

287

288

2010 SWDNB different ( $36 \mathrm{~km}$ minus 12km) winter

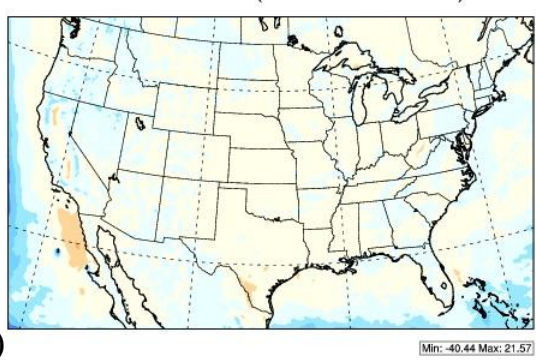

(g)

2010 SWDNBC different ( $36 \mathrm{~km}$ minus $12 \mathrm{~km})$ winter

289

(i)

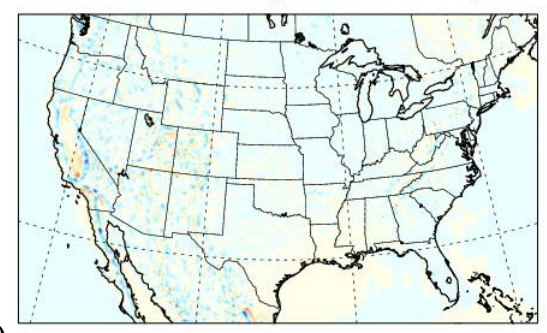

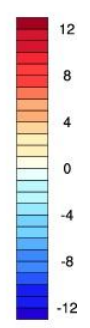

(b)
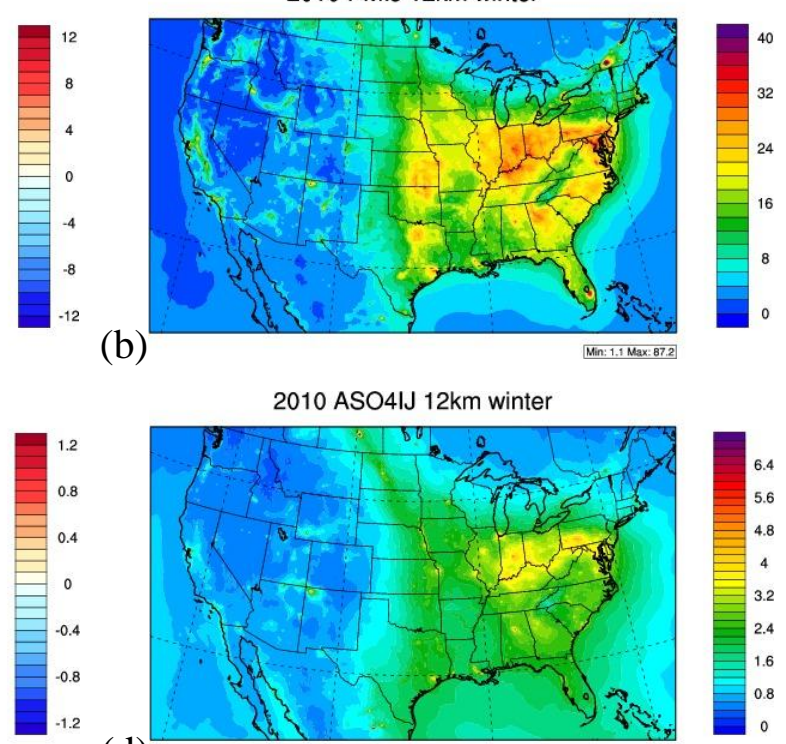

(d)

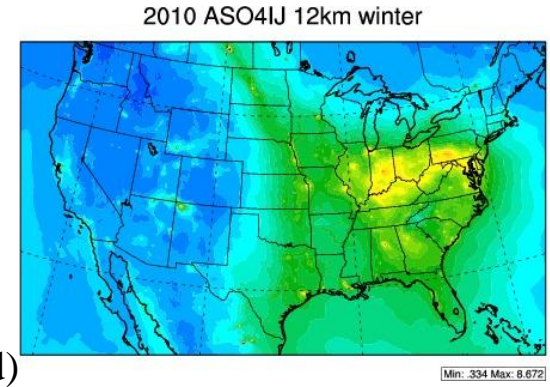

2010 SW_AOD 533 12km winter

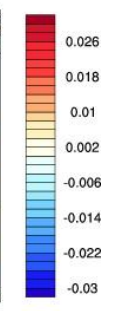

(f)
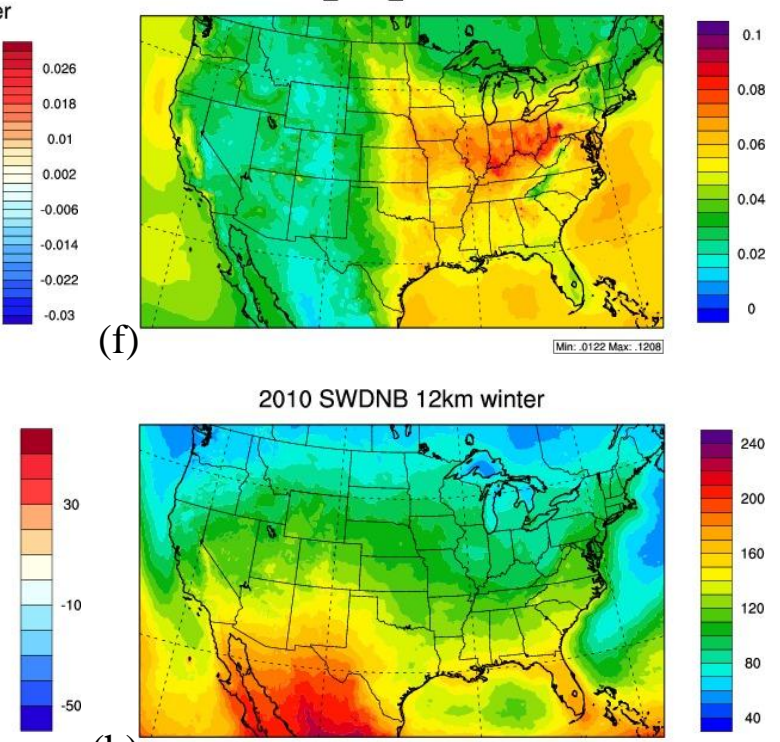

(h)
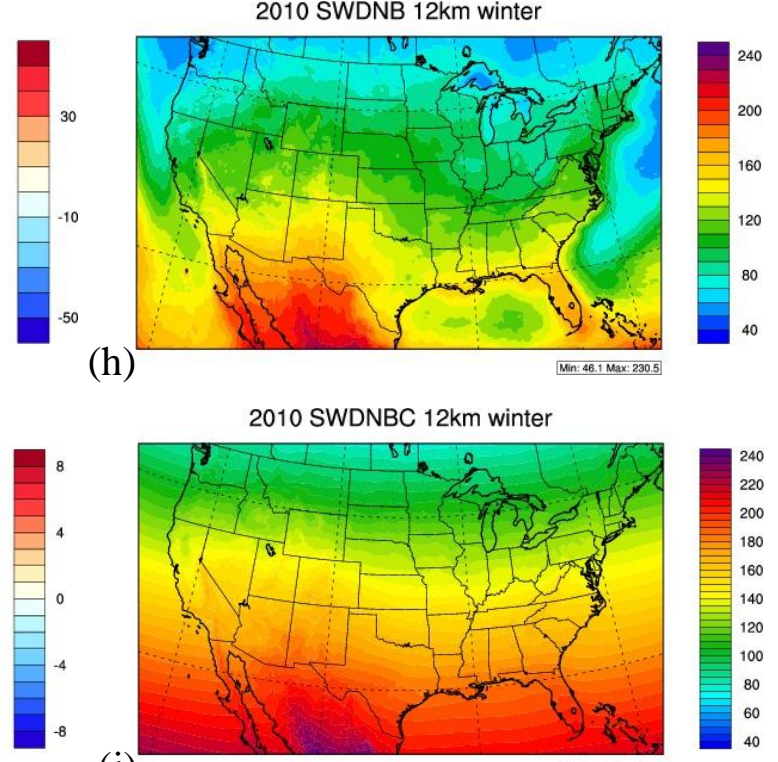

290 Figure 4: As in Figure 2 but for winter (Nov, Dec and Jan) 2010 
291

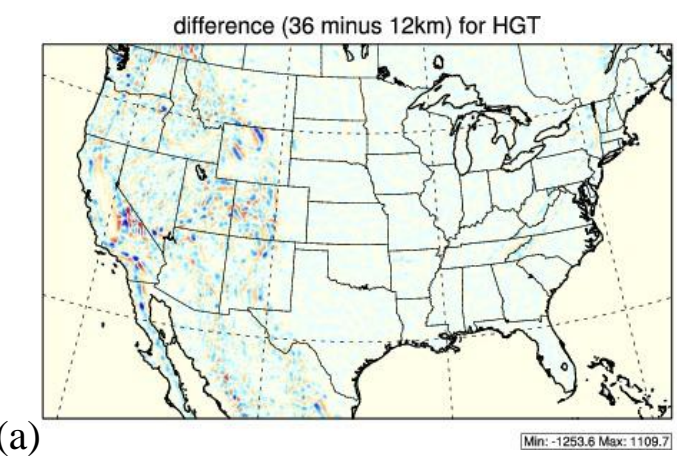

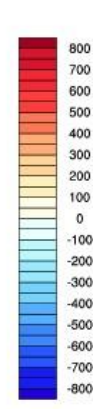

(b)

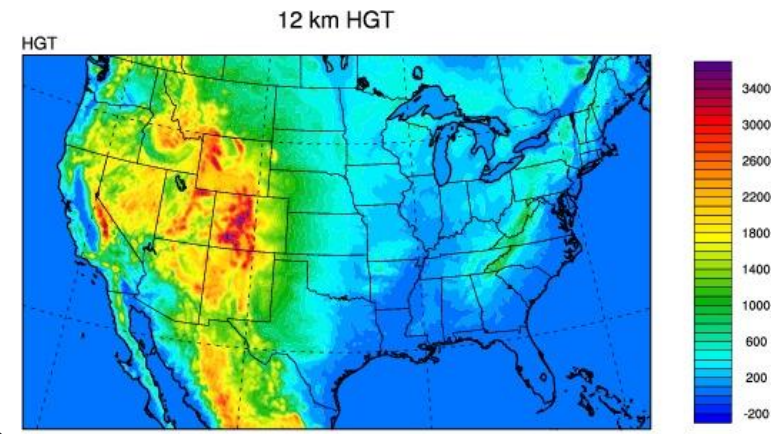

Min: -113 Max: 3729

292 Figure 5: The left panel is the difference of the terrain height between the $36 \mathrm{~km}$ and $12 \mathrm{~km}$ 293 simulations and the right panel is the $12 \mathrm{~km}$ terrain height.

294

295

296

297

298

299

300

301

302

303

304

305

306

307

308

309

310

311

312

313

314

315 
316

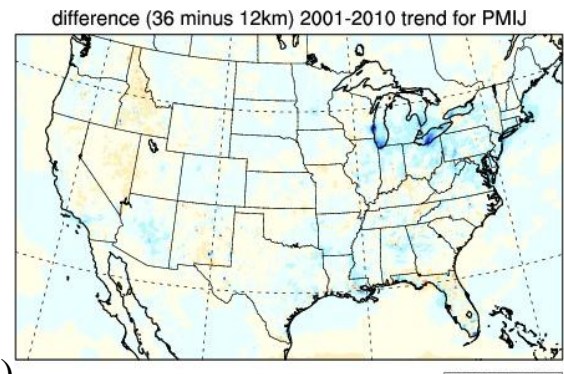

(a)

317

(c)

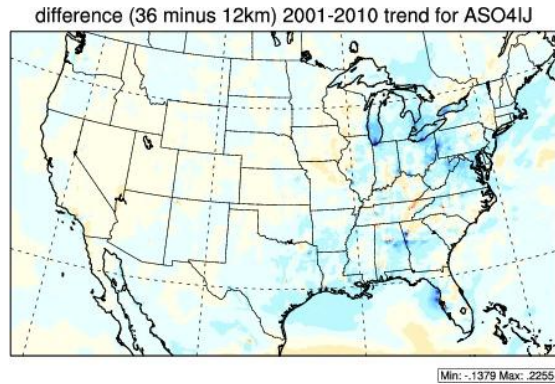

difference (36 minus 12km) 2001-2010 trend for SW_AOD_533

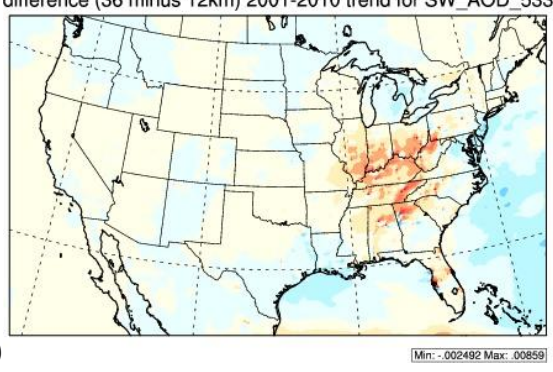

(e)

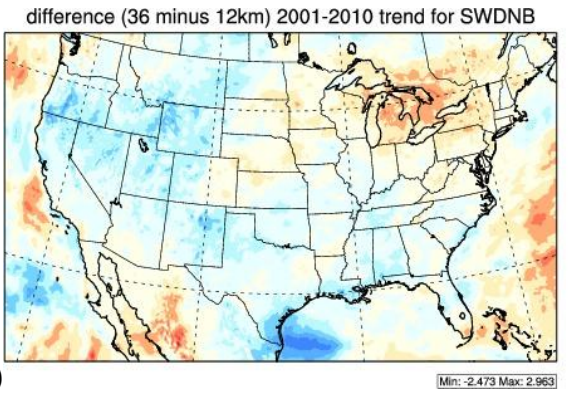

319

(g)

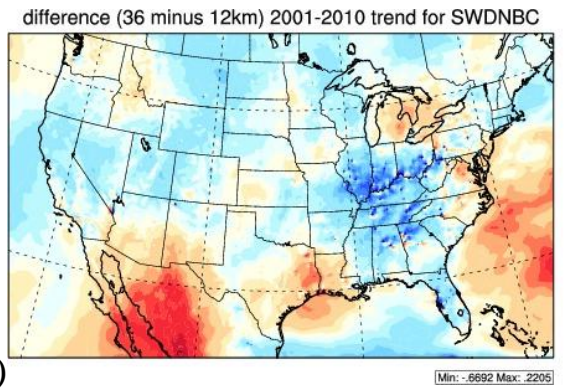

(i)

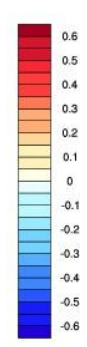

(b)
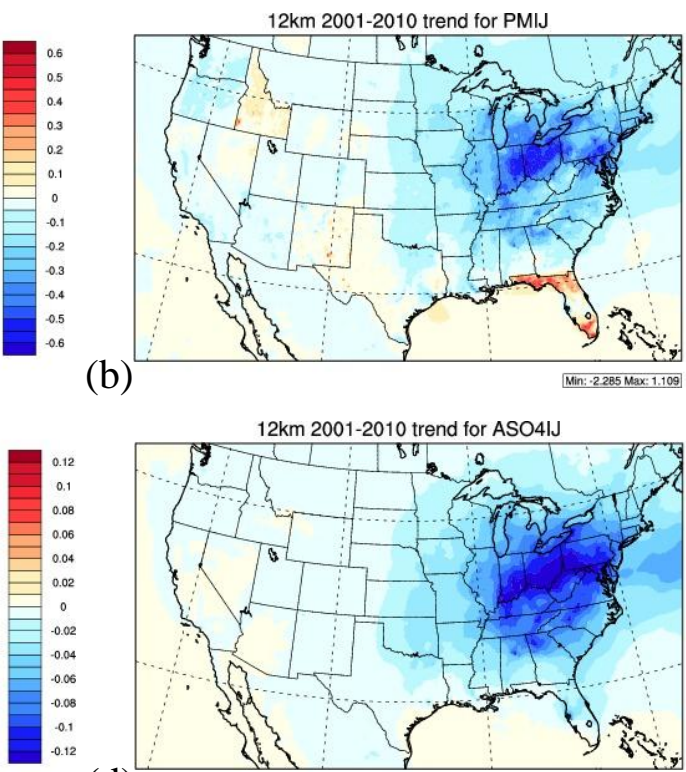

(d)
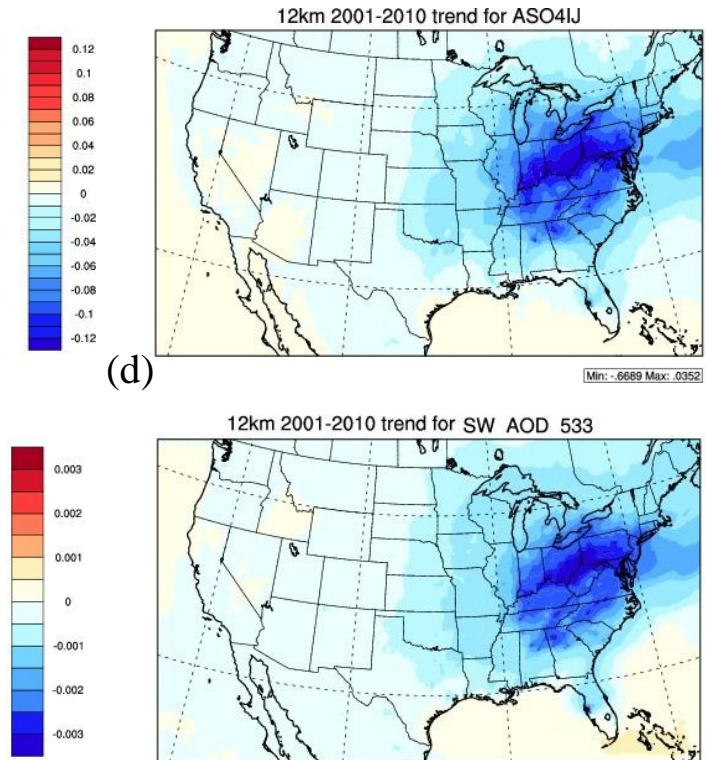

(f)
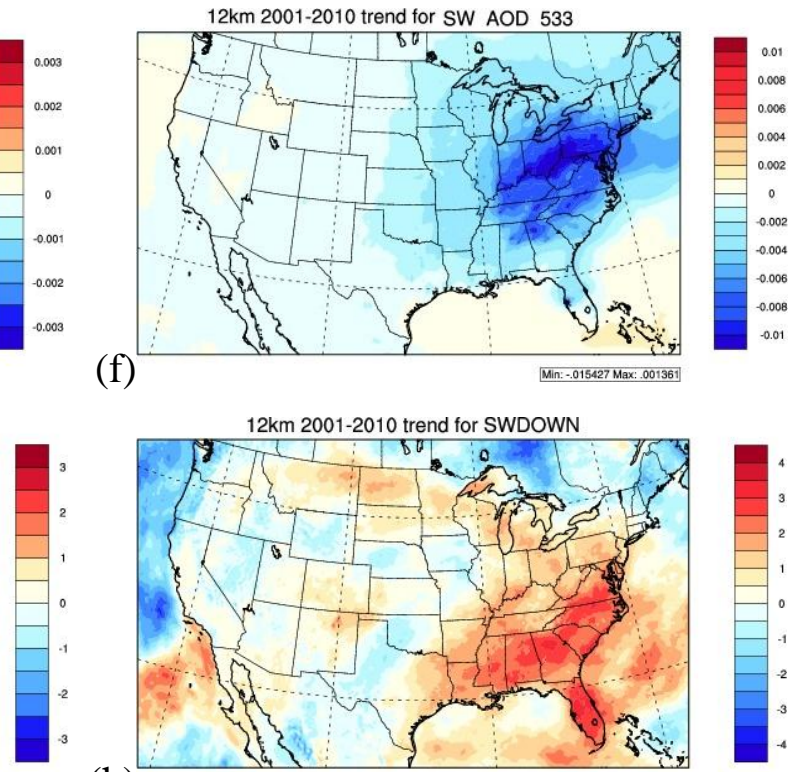

(h)
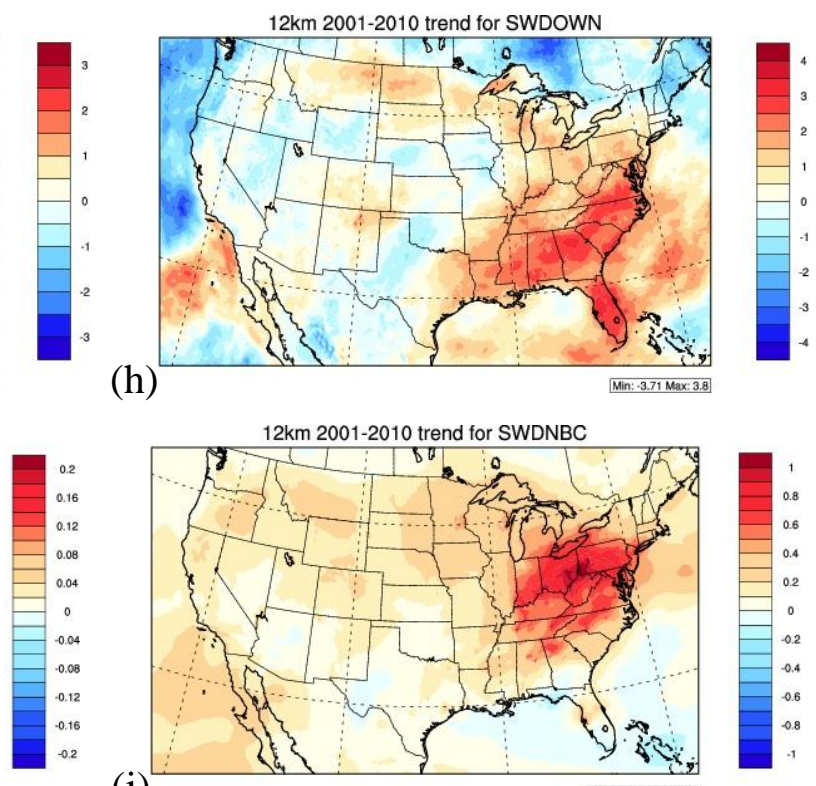

(j)

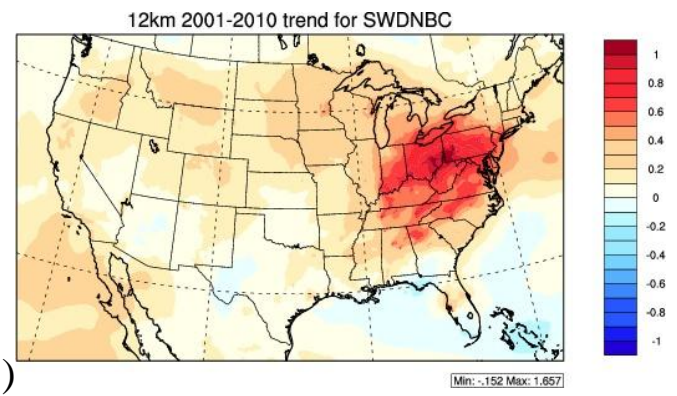

321 Figure 6: The first column shows the differences of $2001-2010$ summer trends in $\mathrm{PM}_{2.5}, \mathrm{SO}_{4}^{2-}$, 322 AOD, all-sky and clear-sky SW radiation between the two simulations (36 km trend minus 12 $323 \mathrm{~km}$ trend) and the second column shows the corresponding trends from the $12 \mathrm{~km}$ simulation. 


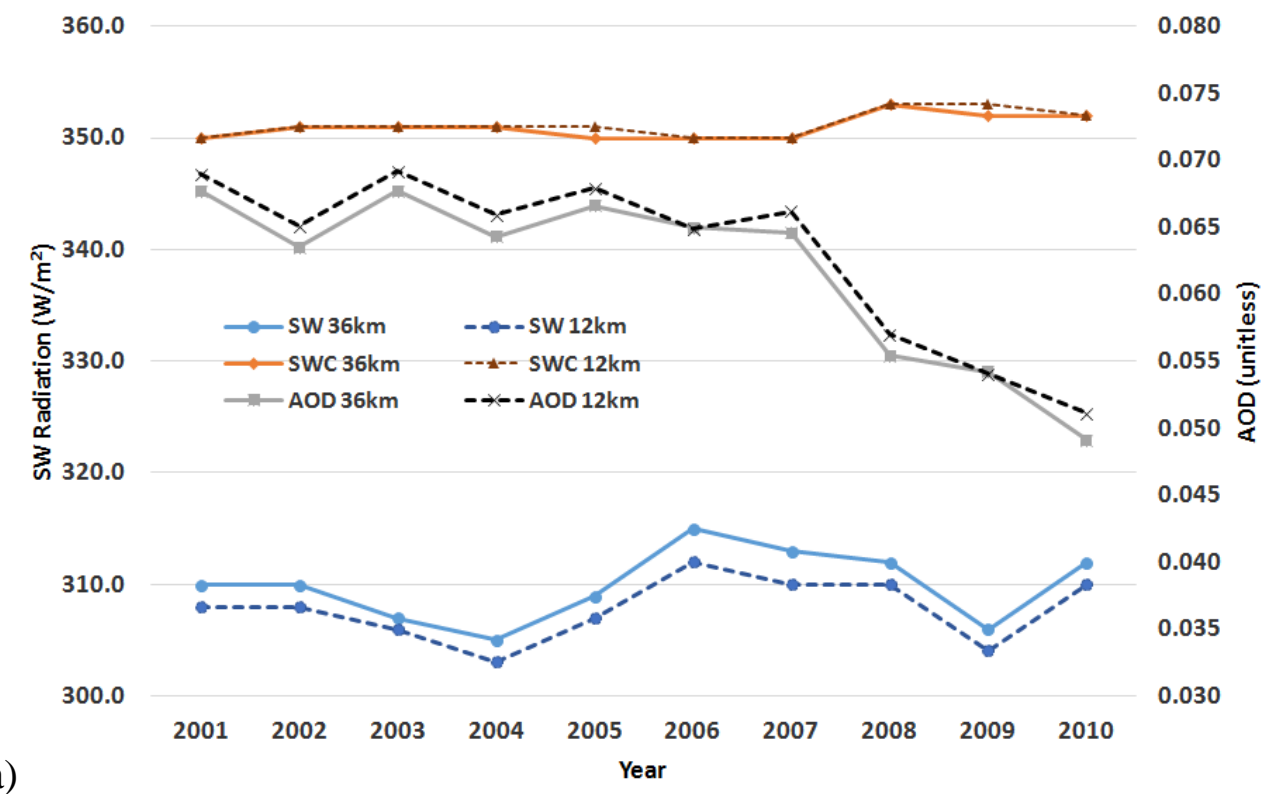

324 (a)

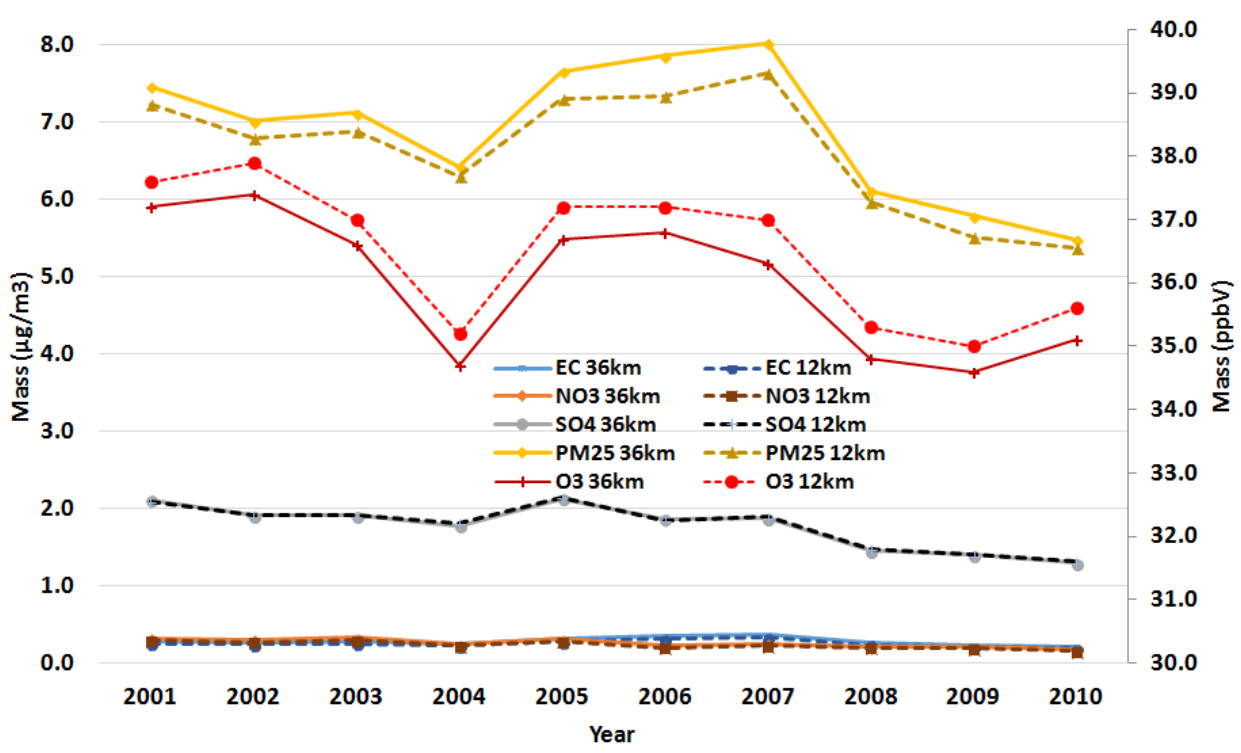

326 Figure 7: (a) Summer (June, July and August) mean values spatially averaged over all non-water 327 grid cells for the $12 \mathrm{~km}$ and $36 \mathrm{~km}$ simulation.s (a) all-sky and clear-sky SW radiation (both on 328 the left axis) and AOD (right axis). (b) $\mathrm{EC}, \mathrm{NO}_{3}^{-}, \mathrm{SO}_{4}^{2-}$ and $\mathrm{PM}_{2.5}$ (left axis) and $\mathrm{O}_{3}$ (right axis). 